\title{
Simuliidae and the Transmission and Control of Human Onchocerciasis in Latin America
}

* British Museum (Natural History), Department of Entomology, Cromwell Road London SW75BD (U.K.).
A. J. Shelley*

Neste trabalho são discutidos os fatores que interferem na suscetibilidade de espécies de simulideos atuarem como hospedeiros do Onchocerca volvulus $e$ de transmitir a filária em condiçōes naturais. Acredita-se que a presença ou não da armadura do cibário pode ser um fator central, que anteriormente foi subestimado. Este aspecto é discutido em relação ds opçōes em voga de métodos de controle na oncocercose. São também discutidos os estudos epidemiológicos correntes, a dinâmica de transmissāo e principais medidas de controle para cada foco de oncocercose na América Latina.

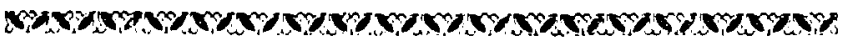

The role of simuliid blackflies in the epidemiology and control of onchocerciasis in Latin America was recently comprehensively reviewed (Shelley, 1988). The overall situation since then remains largely unchanged except that control of onchocerciasis using ivermectin has been started in the onchocerciasis foci of Mexico and in the Yepocapa focus of Guatemala and further data are available on the foci of Ecuador and northern Venezuela. The purpose of this paper is to update the 1988 review and provide a synthesis of the principal factors that affect parasite transmission indicating how these should influence vector control strategies in the different foci of Latin America.

Each of the twelve vector morphospecies, several of which are now known to be complexes of sibling species (Table I), is unique in its host capacity and biology and these two parameters need to be considered for each focus when control strategies are being formulated. It is now timely to examine these strategies because of the introduction of ivermectin for parasite control over the last few years in Latin America and the results of preliminary work in Africa that have shown this filaricide not to be the panacea for human onchocerciasis originally envisaged (Duke, 1990). Vector control is still a major component of 
onchocerciasis control together with ivermectin in many parts of West Africa where the efficient vector Simulium damnosum s. $l$. occurs. In Latin America, the decision to use vector control to supplement ivermectin treatment of infected individuals depends on the efficiency of the individual vectors involved. The factors that affect Onchocerca volvulus transmission and onchocerciasis control are first discussed followed by a review of onchocerciasis transmission and actual and suggested methods for its control in each focus.

\section{FACTORS AFFECTING ONCHOCERCIASIS TRANSMISSION}

Many factors that affect or involve both the parasite and simuliid host influence the degree of severity of onchocerciasis in Latin America (Shelley et al., 1987). In the parasite they include the pathogenicity of the strain or population of $O$. volvulus, its accessibility to the vector in terms of its density and prevalence in the human population, and its distribution in infected individuals in relation to the preferred biting site of the vector. In the vector the factors that affect the efficiency of a simuliid species to transmit $O$. volvulus may be divided into two groups: those that influence the ability of the fly to host the parasite (host capacity) and those that interact with its host capacity and thereby influence the ability of a species to transmit the parasite (vector capacity).

\section{Host capacity}

Factors that affect host capacity are the presence or absence of a cibarial armature in the fly, the presence or absence of intrinsic barriers to a synchronous development cycle of the parasite in the fly, attractants in the saliva of flies that cause concentration of microfilariae at the biting site, and the speed of formation of the peritrophic membrane. An additional factor, not yet investigated in Latin America, is the production of acquired resistance to further filarial infection by previously parasitised flies, as was first shown to occur in two species of British blackflies infected with the bovine filaria $O$. lienalis (Ham, 1986). Only the two former factors have been well studied for species of Latin America. 
TABLE I

The Simuliid Vector Species of Onchocerciasis in Latin America

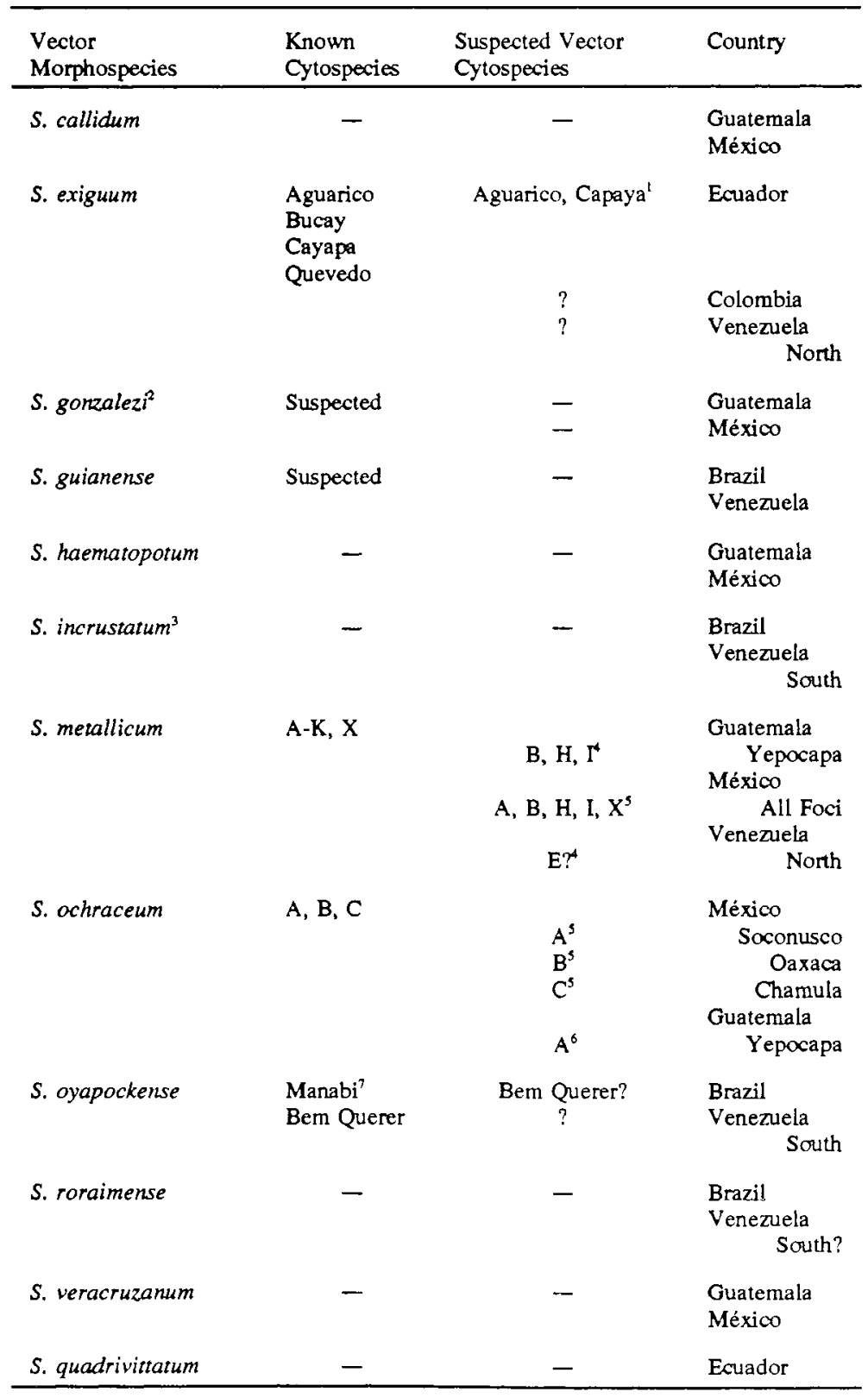

Adapted from Shelley (1988). New data sources: ' Shelley et al. (in press a);

${ }^{2}$ Porter \& Collins (1988); ${ }^{3}$ Shelley A. J. et al. (in press b); ${ }^{4}$ Conn (1988);

${ }^{3}$ Millest (1989); ${ }^{6}$ Hirai, H., Procunier, W.S., Uemoto, K. \& Ochoa, A. J. O.

(unpublished data); ? Procunier et al. (1987). 
Vector simuliid species in Latin America may be divided into two groups according to the effect that the presence or absence of a cibarial armature has on the fly's host capacity, as shown by experimental infection on flies with O. volvulus. In those species with an armed cibarium host capacity is always low because the cibarial teeth damage many microfilariae ingested during blood feeding by the fly and prevent their development to infective L3 larvae (Duke, 1970; De Leon \& Duke, 1966; Omar \& Garms, 1975; Shelley \& Arzube, 1985; Shelley et al., 1987; Takaoka et al.,1984a, b). Thus in S. ochraceum s. l., S. oyapockense s. l., S. quadrivittatum and S. haematopotum up to only $2 \%$ of microfilariae will fully develop. High host capacity is only found in species with no cibarial armature (S. callidum, $S$. exiguum s. l., S. metallicum s. l., S. guianense) since microfilariae can pass through the cibarium unscathed, and up to $60 \%$ develop to L3 larvae (Table II).

However, a lack of cibarial teeth does not always signify high host capacity (Table II) since intrinsic barriers may exist that prevent full development of microfilariae to infective larvae. Thus the Cayapa cytospecies of $S$. exiguum is a highly efficient host to $O$. volvulus in Ecuador with most microfilariae developing rapidly to the $\mathrm{L} 3$ stage within 5-8 days (Shelley \& Arzube, 1985; Shelley et al., 1987). In Colombia, where a different cytospecies of $S$. exiguum probably occurs, the vector is less efficient since parasite development in the fly is partially asynchronous resulting in a lower number of microfilariae reaching the infective larva stage in the same time period (Shelley et al., 1987; Tidwell et al., 1980). Increased asynchrony of the development cycle results in an even lower host capacity in S. exiguum s. $l$. of the northern Venezuelan foci (Duke, 1970; Shelley et al., 1987) where a different cytospecies probably occurs and where the development period of the few microfilariae that do not become stunted is prolonged. Similarly, S. metallicum s. $l$. populations in Guatemala and Mexico are poor hosts compared with populations in northern Venezuela, again probably attributable to the presence of different cytospecies. Though a high proportion of microfilariae eventually develop to L3 larvae in the northern Venezuela foci partial asynchrony of the development cycle retards parasite development and here $S$. metallicum $s$. $l$. is a less efficient vector than the Cayapa form of S. exiguum in Ecuador (De Leon \& Duke, 1966; 


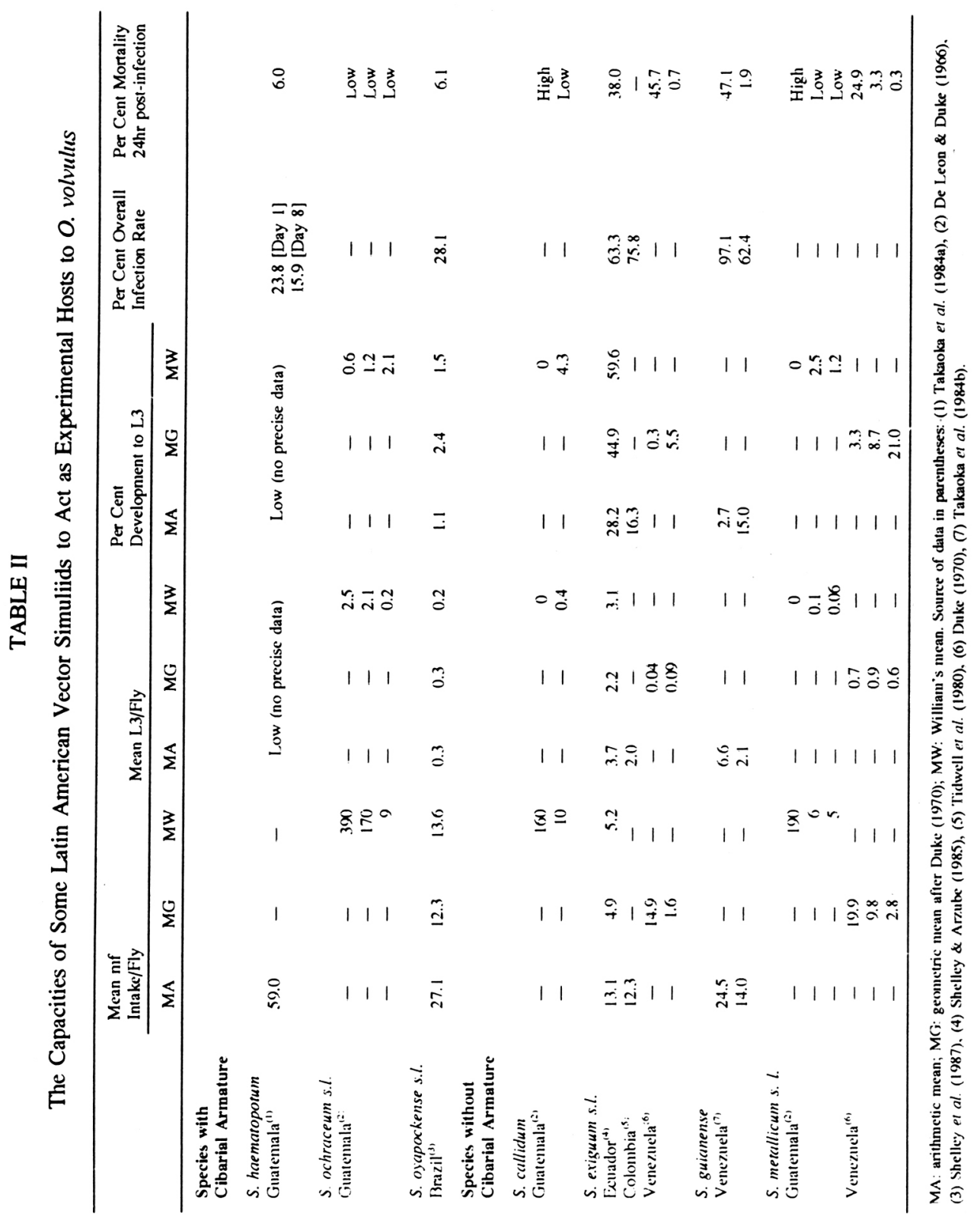


Duke, 1970; Shelley et al., 1986, 1987). Asynchrony in the parasite development cycle in species with armed cibaria has only been recorded in S. haematopotum (Takaoka et al., 1984a).

The number of parasites ingested with the blood meal acts in conjunction with cibarial morphology to influence the final host capacity of the fly population. The number of microfilariae ingested is related to two factors: parasite density in the host's skin and the relative concentration effect produced by different fly species. This concentration effect has been demonstrated by De Leon \& Duke (1966), Shelley et al., (1979) and Takaoka et al. (1984a), who postulate that a substance in the saliva of the fly inoculated during feeding is responsible for attracting microfilariae to the site of the bite and that this effect varies with species. A similar enhancing factor that increases the parasite's chances of transmission has been found in the saliva of phlebotomine vectors of Leishmania (Titus \& Ribeiro, 1990). It has been shown that in species with unarmed cibaria such as $S$. callidum, $S$. exiguum $s$. $l$. and $S$. metallicum s. L. (De Leon \& Duke, 1966; Duke, 1970) and S. guianense (Takaoka et al., 1984b) fly mortality rates increase with an increase in microfilarial intake, directly linked to skin microfilarial densities and the concentration effect. The absence of cibarial teeth in these species allows all ingested parasites to reach the mid gut intact and from there invade other body organs causing the host to die from hyperparasitisation if microfilarial intake is high (Omar \& Garms, 1977). In contrast, the ingestion of large numbers of microfilariae by flies with armed cibaria has a less drastic effect on fly mortality because the cibarial teeth damage many of the parasites ingested during blood feeding and consequently prevent their further development. This protective effect on the parasite has been most clearly demonstrated in the primary vector $S$. ochraceum $s$. $l$. in Guatemala (De Leon \& Duke, 1966; Collins et al., 1977). The cibarial armature is, therefore, fundamental when considering the effect that individual species have on disease endemicity and control. Species with no cibarial teeth and high host capacities are able to transform a state of hypoendemicity to meso - and hyperendemicity relatively rapidly (e. g. S. exiguum s. $l$. in Ecuador), whereas species with armed cibaria, and consequently low host capacities, have little effect on parasite density and prevalence rates 
over the short term (e. g. S. oyapockense s. $l$. in Brazil). The converse is probably true in hyperendemic situations in that species with unarmed cibaria are unprotected from high microfilarial intake and hence show higher mortality rates, whereas those species with armed cibaria have lower mortalities and are more effective vectors when biting in high numbers.

\section{Vector capacity}

The vector capacity, quantified as the annual transmission potential (ATP) or theoretical number of infective bites received by a man in one year, is thus determined by the interaction of host capacity with the other factors affecting both fly and parasite such as seasonal biting densities, degree of zoophily, site of biting on body, duration of bite. Thus, a species with a high host capacity will not act as an efficient vector and will have a low ATP if man-vector contact is low because of low bitting rates due to either small population size or a predilection for zoophily. Conversely, a high ATP may occur in a species that has a low host capacity if it is highly anthropophilic and has high man biting rates, if high densities of parasites are available in man for transmission. In Africa the use of ATPs for quantifying transmission is routine, whereas in Latin America this method has been used only recently in Guatemala and Mexico. The effects of the various factors on vector capacity are summarised in Figure 1.

\section{CONTROL}

Onchocerciasis control ideally aims at reducing the parasite in man to a level at which it has no pathogenic effect and at which the vector cannot be responsible for a rapid recrudescence of the disease. The level at which the disease is no longer seriously pathogenic to man can be related to skin microfilarial densities and the ATP. In Africa these levels have already been calculated and are used as threshold targets in the Onchocerciasis Control Programme. However, the parasite level at which transmission only becomes sporadic has not yet been measured in Latin America because of the large number of vector species, each unique in its vector capacity and biology. It is postulated that in foci in which species with 
unarmed cibaria and high host and vector capacities occur recrudescence may be rapid even if parasite densities are low. Evidence for this hypothesis comes from recent work in Ecuador where Guderian et al. (1988) showed that the disease moved from hypoendemicity to mesoendemicity in six years at a locality where the Cayapa cytospecies of $S$. exiguum was shown to have high host and vector capacities (Shelley, 1988; Shelley et al, 1986, in press b). Conversely, species with armed cibaria do not produce significant changes in hypoendemic areas and only show high vector capacities if biting rates and parasite levels are high. Thus, in Brazil onchocerciasis remained hypoendemic over a ten year period (Moraes et al., 1986) because of the low host capacity of $S$. oyapockense s. $l$. despite high biting densities (Shelley et al., 1987). This evidence suggests that control in areas with vectors with high host and vector capacities needs to be indefinite (e. g. Ecuador), whereas in hyperendemic areas with vectors showing low host but high vector capacities reduction of the parasite in man to a low, as yet undetermined critical level, and then cessation of control would be sufficient (e. g. Central America). This hypothesis needs to be tested in the field; if proven to be correct it would reduce costs and time spent in unnecessary vector contro! in some foci.

The only two practical methods of onchocerciasis control available are the chemotherapeutic treatment of infected individuals and control of the vector through larviciding. Ivermectin has now largely replaced diethylcarbamazine and suramin as a control drug because of its relative lack of side effects, apparent efficacy and ease of administration (only one tablet required annually). Although at first sight ivermectin would be the method of choice it cannot be universally administered, being unacceptable for certain categories of people (Duke, 1990). The use of DEC for these categories as occurs in Mexico (Dr. R. San Clement, pers. comm.), will still not give blanket coverage for infected individuals and hence larviciding is required to complement parasite control if the vector species has a high host capacity. Modern larviciding methods (Laird, 1981) focus on the use of the organophosphate temephos and delta endotoxins produced by Bacillus thurigiensis var. israelensis serotype H14. (For reviews on ivermectin see Hudson, 1985; Gaugler \& Finney, 1982; Taylor \& Greene, 1989). The use of ivermectin, with or without accompanying vector control is discussed for each focus.

Cadernos de Saúde Pública, RJ, 7(3): 310-327, jul/set, 1991 


\section{FIGURE I}

Factors Affecting Vector Capacity of Simuliidae

to $O$. volvulus in Latin America

PARASITE IN MAN

Parasite density in skin

Parasite prevalence

in community

Parasite distribution in body

\section{HOST CAPACITY OF FLY}

Concentration effect

Presence/absence of cibarial teeth

Speed of formation of peritrophic membrane Synchrony of paradise cycle in fly Acquired immunity to

parasite
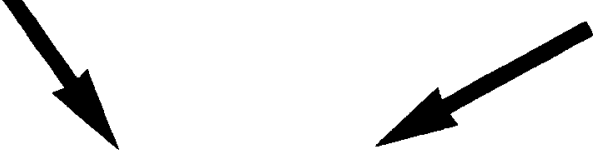

\section{VECTOR CAPACITY}

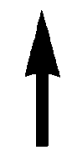

BIOLOGY OF FLY

Seasonal and daily biting densities

Degree of zoophily

Biting site on man

Duration of biting

ONCHOCERCIASIS TRANSMISSION AND CONTROL IN LATIN AMERICA

\section{Central America foci}

Of the five foci in Central America only the Yepocapa focus of Guatemala and the South Chiapas or Soconusco focus of southern Mexico have been sufficiently well 
researched to produce data for epiciemiological assessment and control. In these foci onchocerciasis transmission is principally due to $S$. ochraceum $s$. l. although $S$. metallicum s. l., S. callidum, S. haematopotum, S. gonzalezi and $S$. veracruzanum appear to be involved to a lesser extent in some localities. Control in Mexico is limited to the use of ivermectin and DEC but in Guatemala ivermectin and local vector control are used.

The host capacity of $S$. ochraceum $s$. $l$. is low because of the presence of cibarial teeth (Table II) and for this reason the finding of three sibling species in $S$. ochraceum in Central America, each of which may have different biting behaviour and susceptibility to the parasite, is unlikely to have such a significant effect on transmission as occurs in cytospecies with unarmed cibaria. Simulium ochraceum $s$. $l$. is, however, an efficient vector in areas hyperendemic for the disease due to its high anthropophily and high biting rates, which counterbalance its low host capacity. However, the host capacities of populations of $S$. ochraceum $s$. $l$ from non endemic, hypoendemic and hyperendemic foci have been found to be similar in areas where high biting densities occur (De Leon \& Duke, 1966; Garms, 1975). A crucial factor affecting transmission is, therefore, the availability to flies of $O$. volvulus in the human host. The critical level of the parasite reservoir at which transmission becomes continuous instead of sporadic, and hence responsible for an increase in endemicity and public health importance of the disease, still needs to be determined. It should, therefore, be sufficient to reduce the parasite density in man to below this threshold by using ivermectin. Once the disease has been reduced to this level high biting rates would only be responsible for sporadic parasite transmission and the hypoendemic situation would persist for some time rendering continuous control unnecessary. The efficacy of control measures could be regularly monitored with parasitological surveys.

The other vector species in the foci of Central America have low vector capacities because of low biting rates, mainly zoophilic behaviour or low host capacity. However, further work is necessary to establish whether any of the five cytospecies of $S$. metallicum in this region are sufficiently anthropophilic and susceptible to the parasite to be of local importance epidemiologically, since previous work was carried out before a species complex had been detected.

Cadernos de Saúde Pública, RJ, 7(3): 310-327, jul/set, 1991 


\section{Northern Venezuela foci}

Onchocerciasis is no longer a serious public health problem in the Caripe and Altamira foci of northern Venezuela, although recent reports (Tada, 1985) underestimate the prevalence of the disease (Botto, 1990). Although no comprehensive pre - and post - control data are available it would appear that effective chemotherapy, the relatively poor vector capacity of the primary vector $S$. metallicum $s$. $l$. and possibly the effects of agricultural insecticides on larvae, all contributed to the success of control campaigns. Although $S$. metallicum $s$. $l$. was anthropophilic and bit man in large numbers, its host capacity was relatively low because of asynchronous and delayed parasite development. The other anthropophilic species present, $S$. exiguum $s$. $l$, would have been a poor vector because of the highly asynchronous parasite cycle, low man-biting rates and its predominantly zoophilic habit. Control of onchocerciasis in the remaining infected individuals should be feasible using ivermectin.

\section{Amazonia focus}

This is the most isolated of the Latin American foci and is situated in southern Venezuela and north-western Brazil. No control campaigns were initiated after suramin treatment of several Indians in Brazil had to be curtailed because of side effects. The focus consists of a central, highland, mainly hyperendemic zone and a peripheral, lowland, mainly hypoendemic zone (Basañez et al., 1988; Shelley, 1988; Shelley et al., in press a). Transmission data for the highland zone are scanty, but $S$. guianense with an unarmed cibarium would appear to be the primary vector because of its high host capacity, and $S$. incrustatum with an armed cibarium the secondary vector because of its host capacity. Both local vector control and the use of ivermectin would be necessary on a regular basis because of the high host capacity of $S$. guianense. However, it is doubtful whether many of the Yanomami Indians would readily accept treatment with ivermectin. In the lowland zone a single vector, $S$. oyapockense $s$. $l$. (here used to include $S$. roraimense, which is morphologically inseparable from $S$. oyapockense $s$. $l$. in the female) has a poor host capacity due to its armed cibarium (Table In) and despite extremely 
high man-biting rates has not increased parasite prevalence rates in Brazil in the last decade because of the low availability of parasites in the human reservoir. Onchocerciasis control is therefore a low priority and not envisaged. The likelihood of dispersal of onchocerciasis, particularly from hyperendemic localities, has increased due to a recent influx of people from non endemic areas. Many of the 40,000 gold miners and military personnel in the Brazilian part of the focus will contract the disease and could be responsible for setting up new foci when returning to other parts of Brazil.

\section{Colombia focus}

Little is known about this focus except that onchocerciasis was hypoendemic on both the initial and follow-up surveys. The only vector species present, $S$. exiguum s. l., had a relatively low host capacity since $O$. volvulus development was asynchronous. No data are available on its biting and natural infection rates.

Control using ivermectin alone, because of the small number of individuals affected, would be sufficient. Further surveys to establish the prevalence of the disease are necessary in the southern border area with Ecuador following the detection of the disease in individuals from this area.

\section{Ecuador focus}

This is currently the most important focus in South America with recent parasitological surveys (Guderian et al., 1988) showing increasing prevalence rates and skin densities of $O$. volvulus. Simulium exiguum Cayapa and Aguarico forms are the primary vectors in hyperendemic areas of the main Santiago focus and the Cayapa form in the peripheral mesoendemic Canandé focus (Shelley, 1988; Shelley et al., 1986). However, the Bucay and Quevedo cytospecies also show high host capacities (Shelley $e t$ al., 1990 , in press, b) and are potential vectors in the non endemic areas where they occur. The high host capacity, anthropophily and biting densities of the Cayapa cytospecies have been responsible for the rapid transition from the hypo - to meso - endemic state of the Canandé peripheral focus. Simulium quadrivittatum is the other 


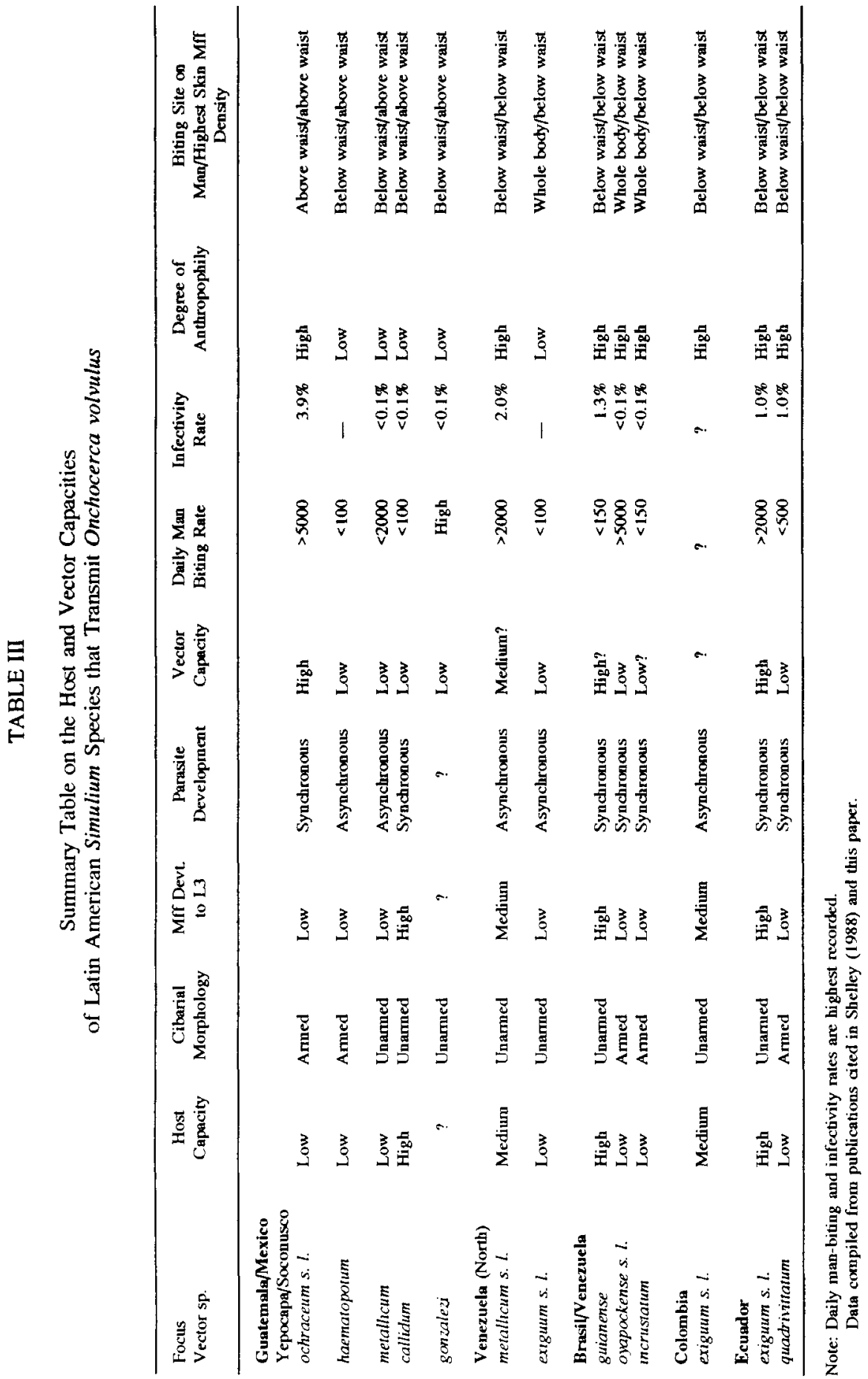


vector, and is probably the principal species involved in transmission in some hypoendemic localities in the main focus. At present it is apparently of limited significance in transmission because of its low host capacity, since it has cibarial teeth, and high biting rates have not yet been recorded. Onchocerciasis is likely to intensify in the known foci because of the vector properties of $S$. exiguum $s$. $l$. noted above. It will disperse to non endemic localities because infected individuals are leaving the affected areas and $S$. exiguum s. $l$. is omnipresent in Ecuador (Shelley et al., 1988). A control campaign using ivermectin alone would be insufficient to control the disease for a prolonged period since reservoirs of the parasite in untreated individuals (e. g. lactating mothers, untreated nomadic Cayapa indians) would be available for the highly efficient vector S. exiguum s. l. to transmit. Drug chemotherapy together with permanent vector control in localities with high man-biting rates would probably be necessary to keep the disease at levels of low public health importance.

A summary of relevant entomological information for the simuliid vector species of Onchocerca volvulus in Latin America is given in table III.

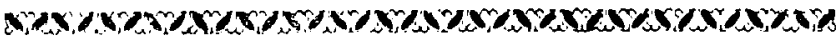

Factors that affect the propensity of a simuliid species to act as a host to Onchocerca volvulus and to naturally transmit this filarial worm in nature are discussed. Presence or absence of a cibarial armature is believed to be a major factor that has been previously overlooked and this is considered in relation to the choice of control methods currently advocated for onchocerciasis. The current epidemiological studies, transmission dynamics and relevant control measures are discussed for each onchocerciasis focus in Latin America.

\section{ACKNOWLEDGEMENTS}

Financial support for field work on which much of this review is based was received from the following Cadernos de Saúde Pública, RJ, 7(3): 310-327, jul/set, 1991 
institutions: British Museum (Natural History), UK.; Ministry of Health and National Council for Scientific and Technological Development, Brazil; National Institute of Hygiene and Tropical Medicine "Leopoldo Izquieta Perez", CEPE/TEXACO and USAID, Ecuador; Pan American Health Organization; and the United Nations Development Programme/World Bank/World Health Organization (Special Programme for Research and Training in Tropical Diseases).

\section{REFERENCES}

BASAÑEZ, M. G., YARZABAL, L., TAKAOKA, H., SUZUKI, H., NODA, S. \& TADA, I. The vectoral role of several blackfly species (Diptera: Simuliidae) in relation to human onchocerciasis in the Sierra Parima and Upper Orinoco regions of Venezuela. Annals of Tropical Medicine and Parasitology 82: 597-611, 1988.

BOTTO, C. La oncocercosis en el norte y en el foco del Alto Orinoco en Venezuela: un estudio comparativo. Revista Mexicana de Parasitologia 3: (abstract no.) 413, 1990.

COLLINS, R. C., CAMPBELL, C. C., WILTON, D. P. \& NEWTON, L. Quantitative aspects of the infection of Simulium ochraceum by Onchocerca volvulus. Tropenmedizin und Parasitologie 28: 235-243, 1977.

CONN, J. A cytological study of the Simulium metallicum complex (Diptera: Simuliidae) from Central and South America. In: Biosystematics of haematophagous insects, (ed. M. W. Service), pp. 221-243, 1988. The Systematics Association Special Volume No. 37, 363pp. Clarendon Press, Oxford.

DE LEON, R. J. \& DUKE, B. O. L. Experimental studies on the transmission of Guatemalan and West African strains of Onchocerca volvulus by Simulium ochraceum, S. metallicum and S. callidum. Transactions of the Royal Society of Tropical Medicine and Hygiene 60: 735-752, 1966.

DUKE, B.O.L. Onchocerca-Simulium complexes. VI. Experimental studies on the transmission of Guatemalan and West African strains of Onchocerca volvulus by Simulium ochraceum, S. metallicum and S. callidum. Ammals of Tropical Medicine and Parasitology 64: 421-431, 1970.

DUKE, B. O. L. Onchocerciasis (river blindness) - can it be eradicated? Parasitology Today 6: 82-84, 1990.

GARMS, R. Observations on filarial infections and parous rates of anthropophilic blackflies in Guatemala, with special reference to the transmission of Onchocerca volvulus. Tropenmedizin und Parasitologie 26: 169-182, 1975. 
GAUGLER, R. \& FINNEY, J. R. A review of Bacillus thuringiensis var. israelensis (serotype 14) as a biological control agent of black flies (Simuliidae). Miscellaneous Publications of the Entomological Society of America 12: 117, 1982.

GUDERIAN, R. H., BECK, B. J., STONE, D. J., ISABEL, K. MACKENZIE, C. D. Onchocerciasis in Ecuador: recent observations in the province of Esmeraldas. Journal of Tropical Medicine and Hygiene 91: 161-168, 1988.

HAM, P. J. Acquired resistance to Onchocerca lienalis infections in Simulium ornatum Meigen and Simulium lineatum Meigen following passive transfer of haemolymph from previously infected simuliids (Diptera, Simuliidae). Parasitology 92: 269. $277,1986$.

HUDSON, J. E. The development of Bacillus thuringiensis H-14 for vector control. Tropical Diseases Bulletin 82: R1-RR10, 1985.

LAIRD, M. ed. Blackflies. The future for biological methods in integrated control. London/New York/ Toronto/Sydney/San Francisco: Academic 399pp.,1981.

MILLEST, A. L. The Simulium ochraceum and S. metallicum species complexes in Mexico: identification, distribution and relation to onchocerciasis. $\mathrm{PhD}$ thesis, Southampton University, UK. Unpublished, 1989.

MORAES, M. A. P., SHELLEY, A. J. \& LUNA DIAS, A. P. A. O foco brasileiro de oncocercose: novas observações feitas nas áreas dos rios Mucajai e Catrimani, Território de Roraima. Memórias do Instituto Oswaldo Cruz 81: 105-109, 1986.

OMAR, M. S. \& GARMS, R. The fate and migration of microfilariae of a Guatemalan strain of Onchocerca volvulus in Simulium ochraceum and S. metallicum, and the role of the buccopharyngeal armature in the destruction of microfilariae. Tropenmedizin um Parasitologie 26: 183-190, 1975.

OMAR, M. S. \& GARMS, R. Lethal damage to Simulium metallicum following high intakes of Onchocerca volvulus microfilariae in Guatemala. Tropenmedizin und Parasitologie 28: 109-119, 1977.

PORTER, C. H. \& COLLINS, R. C. Transmission of Onchocerca volvulus by secondary vectors in Guatemala. American Journal of Tropical Medicine and Hygiene 39: 559-566, 1988.

PROCUNIER, W. S., SHELLEY, A. J. \& ARZUBE, M. Cytological identification of Simulium oyapockense manabi form (Diptera: Simuliidae): a potential vector of onchocerciasis in Ecuador. Tropical Medicine and Parasitology 38: 71, 1987.

SHELLEY, A. J. Vector aspects of the epidemiology of onchocerciasis in Latin America. Annual Review of Entomology 30: 337-366, 1988. 
SHELLEY, A. J. \& ARZUBE, M. Studies on the biology of Simuliidae (Diptera) at the Santiago onchocersiasis focus in Ecuador, with special reference to the vectors and disease transmission. Transactions of the Royal Society of Tropical Medicine and Hygiene 79: 328-338, 1985.

SHELLEY, A. J. ARZUBE, M. \& COUCH, C. A. A biosystematic study of the Simuliidae of the Santiago onchocerciasis focus of Ecuador. Bulletin of the British Museum (Natural History), Entomology 58: 79-130, 1988.

SHELLEY, A. J. CHARALAMBOUS, M. \& ARZUBE, M. Onchocerca volvulus development in four Simulium exiguum cytospecies in Ecuador. Bulletin de la Société Française de Parasitologie 8: 1145, 1990.

SHELLEY, A. J., LOWRY, C. A., MAIA-HERZOG, M., LUNA DIAS, A. P. A. \& MORAES, M. A. P. In press a. Biosystematic studies on the Simuliidae of the onchocerciasis focus of Brazil. Bulletin of the British Museum (Natural History), Entomology.

SHELLEY, A. J., LUNA DIAS, A. P. A., MORAES, M. A. P. \& PROCUNIER, W. S. The status of Simulium oyapockense and S. limbatum as vectors of human onchocerciasis in Brazilian Amazonia. Medical and Veterinary Entomology 1: 219-234, 1987.

SHElleY, A. J., PINGER, R. R., MORAES, M. A. P. \& HAYES, J. Concentration of microfilariae of Onchocerca volvulus by Simulium sanguineum during feeding; use in mapping parasite distribution in the skin. Journal of Medical Entomology 16: 48-51, 1979.

SHELLEY, A. J., PROCUNIER, W. S. \& ARZUBE, M. Direct incrimination of Simulium exiguum Cayapa form as a vector of Onchocerca volvulus in Ecuador. Transactions of the Royal Society of Tropical Medicine and Hygiene 80: 845, 1986.

SHELLEY, A. J., PROCUNIER, W. S. \& ARZUBE, M. In press

b. Desarrollo de la Onchocerca volvulus en dos citoespecies de Simulium exiguum complex (Diptera: Simuliidae) en el Ecuador. Revista Ecuatoriana de Higiene y Medicina Tropical.

TADA, I. ed. A comparative study on onchocerciasis between South and Central Americas. Matsubase, Shimonashikigun, Kumamoto, Japan: Shimoda 80pp., 1985.

TAKAOKA, H., SUZUKI, H., NODA, S., ONOFRE OCHOA, J. \& TADA, I. The intake, migration and development of Onchocerca volvulus microfilariae in Simulium haematopotum in Guatemala. Japanese Journal of Sanitary Zoology 35: 121127, 1984a.

TAKAOKA, H., SUZUKI, H., NODA, S., TADA, I., BASAÑEZ, M. G. \& YARZABAL, L. Development of Onchocerca volvulus larvae in Simulium pintoi in the Amazonas region of Venezuela. American Journal of Tropical Medicine and Hygiene 33: 414-419, $1984 \mathrm{~b}$.

Cadernos de Saúde Pública, RJ, 7(3): 310-327, jul/set, 1991 
TAYLOR, H. R. \& GREENE, B. M. The status of ivermectin in the treatment of human onchocerciasis. American Journal of Tropical Medicine and Hygiene 4: 460-466, 1989.

TIDWELL, M. A., MUÑOZ DE HOYOS, P. \& CORREDOR, A. Simulium exiguum, the vector of Onchocerca volvulus on the Rio Micay, Colombia. American Journal of Tropical Medicine and Hygiene 29: 377-381, 1980.

TITUS, R. G. \& RIBEIRO, J. M. C. The role of vector saliva in the transmission of arthropod borne disease. Parasitology Today 6: 157-160, 1990. 